\title{
We are all part of it: gender bias in public health
}

\author{
Prof. Kolip is associated editor and Prof. Abel is editor-in-chief of this journal
}

"Gender mainstreaming" is on everyone's lips. The Fourth World Conference on Women in Beijing 1995 decided that gender mainstreaming should be a political strategy to achieve equal opportunities for men and women. One year later, the European Union committed itself to this approach. In the meantime gender mainstreaming arrived in numerous fields in politics and its relevance is also discussed in health promotion and public health. The aim of gender mainstreaming is to establish the gender perspective in all relevant fields of politics and policies. In other words: all (political) activities have to be tested with a view to whether they contribute to reducing gender inequality and whether they take into account the different living conditions of women and men. To establish a gender sensitive perspective it is first necessary to see where gender bias in public health research, policy, and practice occurs. Pre-tested instruments are available for evaluating research and intervention applications, and also for critical assessment of gender bias in published works (Eichler et al. 1999; Eichler et al. 2000; Jahn \& Kolip 2002). Such analyses are in their infancy in the German-speaking area. It is due to Judith Fuchs and colleagues that public health research in Germany has become aware of this issue. Their work has aimed to analyse the situation of gender specific health research in Germany and to develop research standards for gender sensitive research in public health. In co-operation with all 5 Public Health Research Networks they conducted a survey of all public health projects, using Margret Eichler's dimensions to identify gender bias in research. They revealed that only a small proportion of projects are gender sensitive. Only a quarter of the projects analysed their data stratified by sex. Although researchers claim to be conscious of the importance of gender issues, few consider these aspects consequently in their own research. Their results also show that a gender sensitive perspective cannot be reduced to just stratifying ("breaking down tables") by sex. Gender sensitive public health research means considering the gender perspective at all stages, i.e., in study design and development, method selection, theoretical embedding, data analysis, and interpretation. Another element of the research project of Fuchs et al. examined how the gender dimension was considered in public health publications (Fuchs \& Maschewsky-Schneider 2002). They analysed 516 original articles in German-language public health journals, published in the years 1990, 1995, and 1999. SPM was one of the journals analysed. The results were alarming: About $73 \%$ of the articles did not mention the sex of the research objects in the abstract. More than half of the articles did not consider gender in the formulation of the research question and only one third drew their conclusions with regard to gender aspects.

While these findings are interesting we need to be aware that public health journals play a key role in the "system of gender bias". Different sources of bias such as language, statistical significance of results etc. have been shown to systematically affect the chances of publication in the medical literature (e.g., Egger \& Smith 2001). Less attention has been given, however, to the interdependence of production and distribution. One could argue that in the system of gender bias in the production cannot be understood separately from the bias in distribution of its (doubly biased) findings. Furthermore, until today very little attention has been given to those "in charge" of the distribution, i.e., the groups and individuals of experts serving as editors and reviewers. While there are a few studies that show profound gender differences, e.g., with respect to quantity and quality of review tasks (e.g., Gilbert et al. 1994; Zuber 2001) the basic conclusion is that there is a clear need for more systematic analysis of editors and reviewers as potential sources of gender bias. In particular, we need to know how and to what degree the readily observable gender differences in the group of editors and reviewers result in significant gender bias (Dickersin et al. 1998).

Soz.- Präventivmed. 48 (2003) 205-206 
Still, we at SPM believe that, rather than waiting for the findings of those long overdue analyses, it would be helpful to increase individual awareness of the fact that as editors and reviewers we are "active" parts, not just observers in this system. If we fail to identify gender (or other) biases we automatically and often un-intentionally contribute to a "onesided" system that deliberately ignores or systematically overlooks important aspects of gender differentiation, perpetuating inadequacies in the system of the production of scientific knowledge. Moreover, there is no such thing as a "neutral" position in this process. Therefore, even if we observe those biases in the manuscripts we are to evaluate, the next challenge is to respond adequately, meaning that we need to intervene. This is why we need a systematic ap- proach to observe and reduce gender bias in public health publications.

At SPM we have recently taken the first steps in this direction by increasing awareness among our associate editors. More is to come as we will soon develop a checklist for reviewers to support their reviewing work with respect to increased gender sensitivity. To complement this we will also be formulating recommendations to authors to be sensitive to different population groups and we want them to be aware about gender aspects and differentiation when presenting their data. While starting with gender, we at SPM are fully aware that other forms of social differentiation such as social class, age and ethnicity will soon need the same degree of attention.

Petra Kolip, Thomas Abel

\section{References}

Dickersin K, Fredman L, Flegal KM, Scott JD, Crawley B (1998). Is there a sex bias in choosing editors? Epidemiology journals as an example. JAMA 280: 260-4.

Egger M, Smith GD (2001). Principles of and procedures for systematic reviews. In: Egger M, Smith GD, Altman DG, ed. Systematic reviews in health care: meta-analysis in context. Williston, VT: BMJ Books: 23-42.

Eichler M, Gustafson D, Pomepetzki M (1999). Moving toward equality: recognizing and eliminating gender bias in health. Toronto Health Canada. (Working paper).

Eichler M, Fuchs J, Maschewsky-Schneider U (2000). Richtlinien zur Vermeidung von Gender Bias in der Gesundheitsforschung. Zs Gesundheitswiss 8 : 293-310.
Fuchs J, Maschewsky-Schneider U (2002). Geschlechtsangemessene Publikationspraxis in den Gesundheitswissenschaften im deutschsprachigen Raum? Ergebnisse einer Literaturreview. Gesundheitswesen 64: 284-91.

Gilbert JR, Williams ES, Lundberg GD (1994). Is there gender bias in JAMA's peer review process? JAMA 272: 139-42.

Jahn I, Kolip P (2002). Geschlecht als Kriterium der Gesundheitsförderung: Grundlagenpapier für Gesundheitsförderung Schweiz. www.gesundheitsfoerderung.ch

Zuber MA (2001). [Underrepresentation of women among peer reviewers and textbook authors in medicine in Germany]. Med Klin 96: 173-80.
Address for correspondence

Prof. Dr. Petra Kolip

Universität Bremen

Fachbereich 11

Postfach 330440

D-28334 Bremen

Tel.: +49-421-5959640

Fax: +49-421-5959668

e-mail: kolip@bips.uni-bremen.de

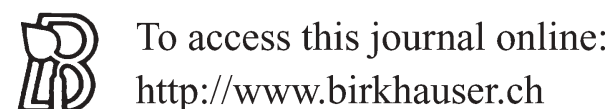

Soz.- Präventivmed. 48 (2003) 205-206

(C) Birkhäuser Verlag, Basel, 2003 